\title{
Retificação cilíndrica do aço VP50 utilizando o rebolo de carbeto de silício verde com a técnica de MQL
}

\author{
Cylindrical grinding of VP50 steel using \\ green silicon carbide grinding wheel \\ with MQL technique
}

\footnotetext{
${ }^{1}$ Universidade Estadual Paulista - UNESP Faculdade de Engenharia de Bauru Av. Luiz Edmundo Carrijo Coube, 14-01, Bauru, SP, Brasil e-mail: kah_miksza@gmail.com, derik-12@hotmail.com, ighorbarili@hotmail.com,bianchi@feb.unesp.br, aguiarpr@feb.unesp.br, hamilton@feb.unesp.br,

${ }^{2}$ Universidade Federal de Uberlândia Faculdade de Engenharia Mecânica, Av. João Naves de Ávila, 2121, Uberlândia, MG, Brasil

e-mail: rsilva@mecanica.ufu.br
}

\begin{abstract}
RESUMO
A retificação é um processo de alta geração de calor, portanto, com seu uso em larga escala, a pesquisa e desenvolvimento de novas técnicas de lubri-refrigeração se fazem necessários, visando respeitar as leis ambientais, preservar a saúde do operador e reduzir custos de produção. Deve-se, então, buscar soluções que mantenham os mesmos parâmetros de qualidade, acabamento e os mesmos efeitos tecnológicos. Um dos métodos propostos para este fim é o MQL (mínima quantidade de lubrificação), que utiliza uma mistura de ar com baixo fluxo de óleo a elevada pressão. O aço a ser utilizado como corpo de prova foi VP 50, muito usado na indústria em moldes para injeção de termoplásticos. O rebolo utilizado foi o de carbeto de silício verde, com ligante vitrificado. Apresentam boas características térmicas, estabilidade química elevada na retificação ferros fundidos, materiais não ferrosos e não metálicos. A análise dos resultados foi feita através avaliação das variáveis de saída do processo, tais como rugosidade, emissão acústica, circularidade, microscopia óptica (para verificação de dano térmico) e microdureza. Dentre os resultados evidenciados, a técnica MQL demonstrou ser superior ao método convencional apenas nos parâmetros de circularidade e desgaste diametral do rebolo, sendo que não houve alteração microestrutural em ambos os métodos de lubrificação.
\end{abstract}

Palavras chaves: retificação cilíndrica; MQL; rebolo de carbeto de silício verde; lubrificação convencional.

\section{ABSTRACT}

Grinding is a high heat generation process that requires large amount of coolant, therefore, its use in largescale lead to research and development of new lubri-cooling techniques to attend technical requirements, environmental laws, to preserve the health of operator and, whenever possible, to reduce production costs. Into this context, it is important to find solutions that maintain the same quality standards, finishing and the same technological effects. An alternative that has been used since the end of $20^{\text {th. }}$ century is the MQL (minimum quantity lubrication) technique, which uses a mixture of air with low oil flow with medium pressure. The steel to be used as a specimen was VP50, widely used in industry for injection mold of thermoplastic. The grinding wheel used was green silicon carbide with vitrified binder that possess good thermal properties, high chemical stability and is recommended for grinding of ferrous and nonferrous materials. The output variables employed in this work were the surface roughness, roundness errors and microhardness. The acoustic emission signal and diametrical wear were also monitored. Analyses of the machined surfaces to evaluate the occurrence of thermal damages were also carried out via optical microscope. Results show that machining with the MQL technique outperformed the traditional coolant delivery method in terms of roundness and diametrical wear. No evidence of microstructural changes in the 
machined surfaces was observed after grinding with both lubri-coolant techniques.

Keywords: cylindrical grinding; MQL; grinding wheel green silicon carbide; conventional lubrication.

\section{INTRODUÇÃO}

A retificação é o processo de usinagem amplamente empregado quando há a necessidade de precisão dimensional e geométrica, principalmente em termos de baixa rugosidade. A retificação é um dos mais complexos processos de usinagem, com um grande número de parâmetros característicos que exercem influência entre si [6]. No processo de retificação, a remoção de material envolve uma grande quantidade de deformação plástica, uma vez que os grãos abrasivos atacam a superfície da peça com ângulos de inclinação negativos [2]. Devido às inúmeras arestas de corte uma grande quantidade de energia é gerada. Essa energia é convertida em calor e as altas temperaturas geram uma das muitas causas de danos nas peças durante a retificação. Os defeitos nocivos causados pelo atrito e pelas deformações plásticas tornam indispensável o uso de fluídos de corte [3].

O uso de fluidos de corte tem como função remover o calor excessivo, lubrificar, remover o excesso de cavacos, mantendo a superfície de corte do rebolo limpa, além de minimizar a corrosão dos materiais envolvidos [8]. Em retificação os objetivos principais do fluido de corte são minimizar os impactos mecânicos, térmicos e químicos entre as partes ativas no processo de abrasão [11] de forma a preservar a integridade na superfície sub-superfície da peça usinada. Em geral, o emprego de fluidos de corte envolve custos elevados para seu descarte e correta manutenção. Suas substâncias são altamente tóxicas tanto para as pessoas como para o meio ambiente. O uso da refrigeração convencional é responsável por agregar um alto custo na retificação, uma vez que ele precisa de uma seleção adequada, manutenção e descarte [3]. Argumentos fortes contra a continuação do uso de fluídos são o alto custo e a poluição, tanto na fase de aproveitamento como no descarte. Esses fatores levam à procura de uma melhor solução para a refrigeração com condições satisfatórias [2].

As duas considerações mais importantes quando se trabalham com rebolos são a refrigeração e a lubrificação. Isso devido à grande geração de calor que prejudica a qualidade superficial e promove perdas dimensionais e geométricas na peça. Além disso, a maioria dos fluidos de corte proporciona um terreno fértil para bactérias, eles também são conhecidos por causar problemas de pele, há também o efeito potencialmente fatal da lixiviação de metais no fluido que afeta os sistemas respiratório e digestivo [6,9].

Portanto, tornou-se necessária a busca de um modelo que, ao mesmo tempo, torne o processo de produção mais barato, atenda aos padrões ambientais e às ótimas expectativas de qualidade obtidas no processo de retificação.

\subsection{O Sistema De Lubri-Refrigeração Convencional}

O sistema convencional de aplicação de fluído de corte consiste no uso em abundância do mesmo através de mangueiras e bocais para banhar a região de contato ferramenta-peça. É possível fazer uma classificação dos fluidos [12] de acordo com as bases líquidas existentes, separando-os em classes, subclasses e grupos pertencentes de acordo com a tabela 1.

Tabela 1: Classificação dos fluidos para processamento de base líquida. [8]

\begin{tabular}{|c|c|c|}
\hline CLASSES & SUBCLASSES & GRUPOS \\
\hline \multirow[t]{3}{*}{$\begin{array}{c}\text { Óleos Integrais (Não miscíveis } \\
\text { em água) }\end{array}$} & Óleos naturais & $\begin{array}{c}\text { Óleos animais, óleos vegetais e } \\
\text { óleos comestíveis }\end{array}$ \\
\hline & Óleos minerais & $\begin{array}{c}\text { Óleos parafínicos, óleos olefini- } \\
\text { cos e óleos aromáticos }\end{array}$ \\
\hline & Óleos sintéticos & $\begin{array}{l}\text { Óleos de hidrocarbonetos satura- } \\
\text { dos e óleos de estrutura complexa }\end{array}$ \\
\hline \multirow[t]{2}{*}{ Fluidos à base de água } & Soluções & $\begin{array}{c}\text { Solução de sal mineral e solução } \\
\text { sintética }\end{array}$ \\
\hline & Emulsões & $\begin{array}{c}\text { Emulsões de óleo (óleos solúveis) } \\
\text { e emulsões sintéticas }\end{array}$ \\
\hline
\end{tabular}


Um sistema de óleo mineral bem planejado pode ser melhor do que uma emulsão à base de água por causa da longevidade do fluido, ótimo lubrificação, baixa corrosão, e ausência de crescimento de fungos e bactérias. Porém, um fluído à base de água possui maior condutividade térmica [5] o que proporciona uma maior troca de calor, que é um ponto importante quando se trata de lubri-refrigeração pelo método MQL.

Apesar dos principais benefícios de reduzir o atrito na operação e promover melhor dissipação de calor, um dos maiores problemas relacionados à usinagem consiste no uso de fluídos de corte com aplicação convencional, devido aos danos ambientais e à sua nocividade à saúde humana [4]. A causa maior desses problemas é a composição química dos fluidos de corte, que contém produtos químicos nocivos à saúde e ao meio ambiente, como por exemplo, cloro, enxofre, entre outros.

A maior parte dos fluídos de corte proporciona um terreno fértil para bactérias que são nocivas para o operador. Os fluídos também podem causar dermatites. Além disso, há o efeito da lixiviação, que é quando os metais pesados presentes no fluído de corte afetam os sistemas digestivo e respiratório humano. Uma vez que o fluído é usado ele contém pedaços de detritos metálicos [9].

\subsection{A Mínima Quantidade De Lubrificação}

Cada vez mais as atenções estão voltadas para a conservação ambiental, e, nesse âmago, um ponto importante é a redução de desperdício de material e matéria prima para a operação industrial. Visando a redução de lubrificante empregado e os custos de fabricação, surgiu a técnica de MQL (minimum quantity lubrification) que emprega uma quantidade muito pequena de fluído para reduzir a fricção entre a ferramenta de corte e a peça usinada [17].

A técnica da Mínima Quantidade de Lubrificação (MQL) em usinagem consiste em borrifar gotas de óleo dentro de um jato de ar comprimido diretamente na zona de corte. Assim, como há pouco fluido de corte, a peça sai praticamente limpa e permite o monitoramento visual do processo [3]. O ar carrega o óleo diretamente (com elevada velocidade) para a zona de corte, o que faz com que esse seja um método bastante eficiente de lubrificação [14].

Embora chamada também de sistema de névoa, ou ainda usinagem próxima a seco, a técnica MQL apenas aproveita a velocidade do ar para conduzir o lubrificante até o ponto desejado e não para criar uma névoa ao redor da peça. Mas é bom ressaltar que o ar comprimido também pode atuar como refrigerante em algumas situações. Há quatro partes principais no sistema de MQL: o aplicador que determina a quantidade de ar e fluido que serão aplicadas; as saídas, que são mangueiras, câmaras ou bocais, onde o lubrificante é liberado; o conjunto de ferramentas, que também incluem os suportes de ferramentas; e por fim a máquina se for o caso, qualquer tipo de programação que impulsiona a unidade MQL é incluída aqui. [17].

De acordo com Alberdi et al. [1], muitas empresas estão usando o sistema MQL na redução de uso de lubrificante para processos como fresamento e torneamento, mas na retificação isto ainda não é possível, pois a retificação gera muito mais calor do que as outras operações devido ao atrito da peça e da ferramenta e o método por MQL não é suficiente para refrigerar a operação, assim as peças fabricadas por este processo ficam suscetíveis a danos bem como o rebolo e a máquina ferramenta

O sistema MQL pulveriza um lubrificante para o fluxo de ar, isso pode ser feito pelo próprio aplicador, ou antes, da pulverização, que é feita na saída do sistema. Quando realizado no próprio aplicador, o sistema é chamado de canal único, isso porque a mistura desce por uma única mangueira ou canal. Já quando ar e lubrificante são conduzidos separados, o sistema é chamado de canal duplo [17].

Existe três maneiras básicas de o aplicador mover e misturar os fluidos. A primeira delas, mais simples, baseia-se no principio de Venturi: o ar é empurrado através de um tubo de Venturi para sugar o líquido a partir do reservatório. Isso cria partículas de $0,5 \mu \mathrm{m}$ a $5 \mu \mathrm{m}$, estes sistemas são de canal único e quase não possuem partes móveis, o que o torna simples e confiável, porém as condições do fluxo de ar na entrada, afeta diretamente a saída. Como acontece com todos os sistemas de linha única, o sistema baseado no Venturi é lento para reagir às mudanças de configurações [17]. O próximo sistema pode suportar um ou mais canais e tem por base uma bomba. Ele usa um tanque pressurizado para forçar o lubrificante através do sistema, a quantidade de lubrificante que circula é controlada por meio de um sistema de medição, que permitem um ajuste separado do fluxo de ar e da quantidade de lubrificante. Esse sistema permite que várias saídas ligadas e reguladas a partir de um único tanque. Entretanto, mesmo com um regulador de pressão teremos variações e fica difícil determinar a quantidade precisa de lubrificante entregue, além disso, o número de saída está limitado pela queda de pressão inerente ao projeto [17].

Por fim o ultimo sistema utiliza uma bomba com um pistão pneumático ou elétrico. Seu modelo de 
deslocamento positivo garante que exatamente o mesmo volume de lubrificante seja medido a cada curso [17].

O fluido de corte pode ser aplicado externa ou internamente à ferramenta, dependendo do processo. A aplicação externa tem por vantagem ser simples, barata e sem nenhum equipamento especial para sua instalação, porém ela apresenta um número limitado de ajustes e dispersão da mistura fora da interface de corte. Já a aplicação interna de fluido permite uma aplicação mais precisa diretamente na interface de corte, porém requer ferramentas especiais e altos custos de instalação [17].

No uso de lubri-refrigeração tradicional a peça fica totalmente coberta por fluído de corte, o que dificulta e algumas vezes impede que a mesma seja observada pelo operado durante o processo de fabricação, no entanto com a aplicação do método MQL é possível a visualização da peça durante todo o processo de usinagem já que ela não está coberta por uma camada de óleo. Na mínima quantidade de lubrificação é usado baixo volume de fluido, ou seja, ao invés da ordem de litros são usados milésimos de litro, aproximadamente de 10 - $100 \mathrm{ml} / \mathrm{h}$ e pressão de 0,4 - 0,65 MPa.

Este trabalho, portanto, traz uma contribuição para a área os usuários de usinagem de metais e também científica apresentado resultados de desvios geométricos (rugosidade da peça e circularidade), como também de microdureza, sinal de emissão acústica do processo e do desgaste diametral do rebolo após a retificação do aço ABNT VP 50 com rebolo de SiC e empregando a técnica MQL.

\section{MATERIAIS E MÉTODOS}

Os experimentos foram realizados em uma retificadora cilíndrica CNC da empresa Sulmecânica, modelo RUAP 515H. Como ferramenta de corte foi utilizado um rebolo convencional de carbeto de silício verde fornecido pela empresa ABRASIPA (GC60L7V), com granulometria de 60mesh, dureza média, grãos meio unidos (estrutura igual a 7) e ligante vitrificado. Este material abrasivo possui elevada dureza, sendo indicado pelo fabricante para a realização deste trabalho, já que não existe na literatura indicações de rebolos para a retificação do aço ABNT VP 50.

Foram realizados 6 ensaios, com aço VP50, com duas réplicas cada, totalizando 18 ensaios. Os corpos de prova de aço ABNT VP 50 possuiam formato cilíndrico com diâmetro externo de 75,0 \pm 0,1 mm, diâmetro interno de $30 \pm 0,1 \mathrm{~mm}$ e espessura de 4,0 \pm 0,1 mm, cuja composição química é apresentada na tabela 3 .

A velocidade de corte foi mantida constante em todos os ensaios e a velocidade de avanço foi variada de 0,25 a 0,75 mm/min. Além da técnica MQL, foram feitos ensaios com a aplicação de fluido de corte pelo método convencional para comparação (tabela 2).

Cada ensaio corresponde a sucessivos mergulhos do rebolo contra a peça, tendo como tempo de faiscamento (sparkout) 1,2 s o que corresponde a uma volta da peça sem avanço do rebolo. Isso foi feito até que fosse removido o volume de 28,26 $\mathrm{mm}^{3}$, critério estabelecido como parada de cada ensaio.

Tabela 2: Resumo das condições de corte empregadas

\begin{tabular}{|c|c|c|c|}
\hline $\begin{array}{l}\text { ENSAIO } \\
\mathbf{N}^{\mathrm{O}} \text {. }\end{array}$ & $\begin{array}{l}\text { VELOCIDADE DE } \\
\text { AVANÇO }(\mathbf{m m} / \mathbf{m i n})\end{array}$ & $\begin{array}{c}\text { SISTEMA DE } \\
\text { LUBRI-REFRIGERAÇÃO / VAZÃo }\end{array}$ & $\begin{array}{l}\text { FLUIDO DE } \\
\text { CORTE }\end{array}$ \\
\hline 1 & 0,25 & \multirow{3}{*}{$\begin{array}{l}\text { Convencional } \\
\text { (1019,0 l/h) }\end{array}$} & óleo solúvel semi- \\
\hline 2 & 0,50 & & sintético \\
\hline 3 & 0,75 & & QUIMATIC ME-I \\
\hline 4 & 0,25 & \multirow{3}{*}{$\begin{array}{c}\text { MQL } \\
(0,1 \mathrm{l} / \mathrm{h})\end{array}$} & De base vegetal, \\
\hline 5 & 0,50 & & Accu-Lube \\
\hline 6 & 0,75 & & LB-1000 \\
\hline
\end{tabular}


Tabela 3: Composição detalhada do aço VP50 (\% em peso) [12]

\begin{tabular}{ccccccccc}
\hline \hline $\mathrm{C}$ & $\mathrm{Si}$ & $\mathrm{Mn}$ & $\mathrm{Mo}$ & $\mathrm{Ni}$ & $\mathrm{Al}$ & $\mathrm{Cu}$ & $\mathrm{S}$ \\
\hline 0,15 & 0,30 & 1,55 & 0,30 & 3,00 & 1,00 & 1,00 & 0,10 \\
\hline
\end{tabular}

O fluido de corte utilizado no método convencional de refrigeração foi óleo solúvel semi-sintético QUIMATIC ME-I, com concentração de 2,5\%, que foi aplicado à uma vazão de 1019 1/h (16,9 1/h) e pressão de 0,4 Mpa. Estes valores de vazão e pressão foram usados para todos os ensaios onde há a refrigeração convencional. Neste fluido de corte há, na sua composição, anticorrosivos, biocidas, fungicidas, alcalinizantes, antiespumantes, tensocitivos não iônicos, alcanolomidas, entre outros.

Já o fluido entregue via a técnica MQL é o Accu-Lube LB-1000, de base vegetal e com características biodegradáveis, fabricado pela ITW Chemical Products Ltda. Este fluido é indicado para a usinagem da maioria dos materiais metálicos, com exceção das ligas de titânio. O equipamento de MQL, também fornecido pela mesma empresa, é composto por: compressor, regulador de pressão, medidor de vazão de ar e bocal. Nesse experimento, o ar possui pressão de 0,6 MPa e a vazão do fluido de corte uma vazão de 0,1 l/h (100 $\mathrm{ml} / \mathrm{h})$. O aplicador utilizado nesta pesquisa foi o ITW Accu-lube 79053D de micro-lubrificação, fornecido pela empresa ITW Chemical Products Ltda. Esse equipamento usa um sistema pulsante de fornecimento do óleo e permite a regulagem da vazão de ar comprimido e lubrificante de maneiras separadas. A vazão de ar comprimido era monitorada com auxílio de um medidor de vazão do tipo turbina modelo SVTG12/12BA4A44BS fornecido pela empresa CONTECH e calibrado a uma pressão de 0,8 MPa.

A medição da rugosidade superficial da peça foi obtida através de um rugosímetro Surtronic3+, da marca Taylor Hobson. Foi adotado um filtro cut-off de 0,8 mm e comprimento de avaliação igual a 5. Cada um dos corpos de prova foi medido três vezes, com uma variação angular entre as medidas tomadas de $120^{\circ}$. Já o desvio de circularidade foi obtido através da utilização de um medidor de circularidade, modelo Talyrond 31C, da marca Taylor Hobson.

O monitoramento do sinal de emissão acústica foi realizado com a utilização de um módulo DM12, Sensis, com um sensor fixado na contra ponta do cabeçote móvel da retificadora, com o intuito de detectar as possíveis variações do sinal de emissão acústica e sua relação com as outras variáveis de saída.

O desgaste linear do rebolo $(\mu \mathrm{m})$ foi medido com o método de impressão do perfil. Este método consiste na retificação de um cilindro confeccionado em aço ABNT 1020, retirando um volume fixo de material, o suficiente para a marcação do desgaste do rebolo, este procedimento pode ser visto conforme a figura 1 . Assim, com o perfil obtido no programa de medição, é possível verificar o desgaste radial do rebolo e, consequentemente, o diametral, através da leitura da dimensão “a” na figura 2. Os desníveis existentes entre as regiões gastas e não gastas do rebolo foram repassados ao corpo retificado, que foi então medido pelo rugosímetro Surtronic3+ e os valores tratados e disponibilizados via o software TalyMap, ambos da marca Taylor Hobson. As medições de microdureza foram realizadas com o auxílio de um microdurômetro Vickers, modelo MicroWizhard versão 1.04 do fabricante Mitutoyo.

As análises de microestrutura foram realizadas no Laboratório de Materiais da própria Faculdade de Engenharia de Bauru-UNESP, necessitando apenas de uma devida preparação dos corpos de prova. Os corpos de prova foram devidamente preparados e sua análise foi realizada com microscopia ótica com ampliação de 500 vezes. 


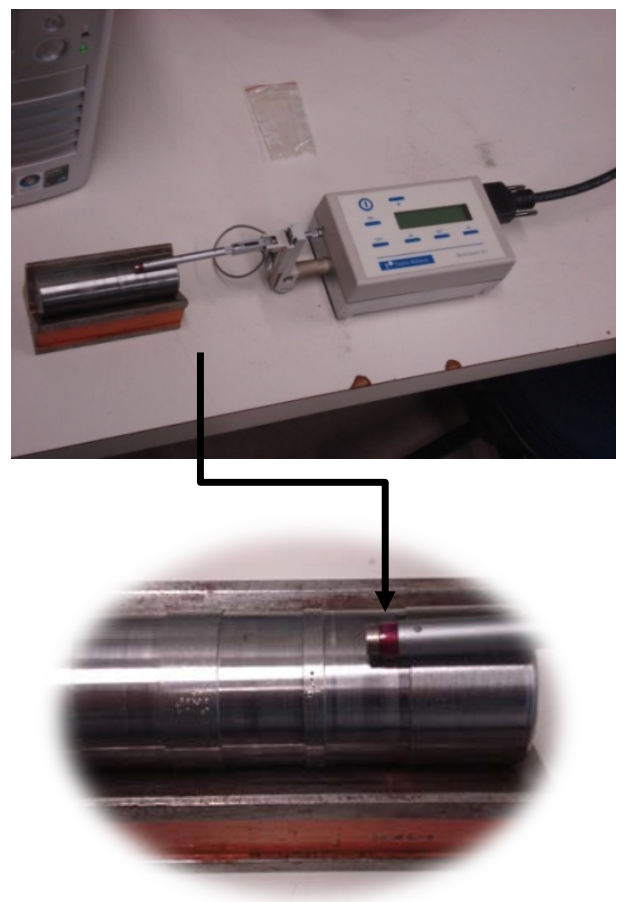

Figura 1: Medição do desgaste diametral do rebolo.

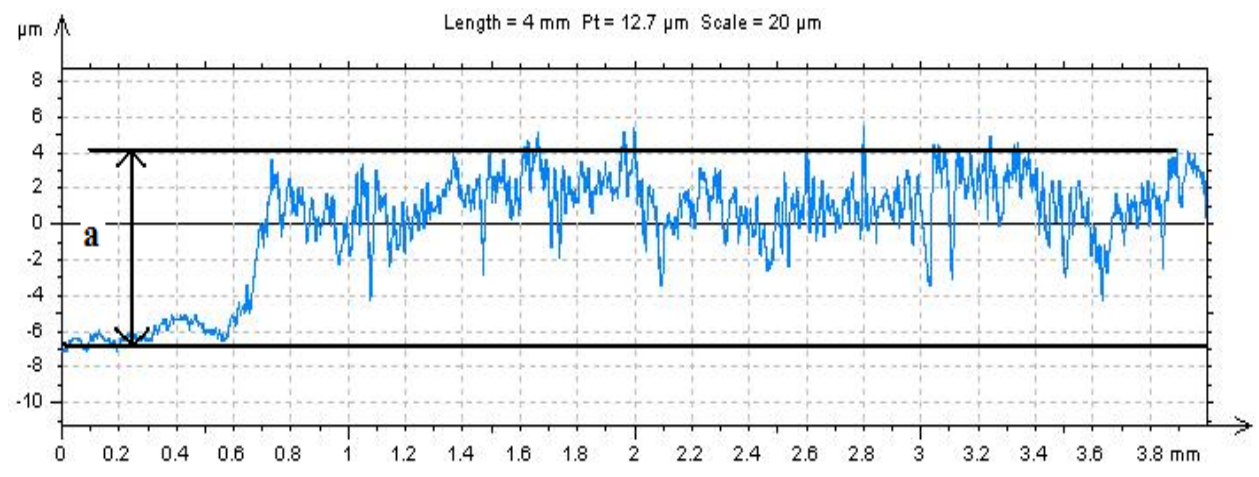

Figura 2: Esquema da medição do desgaste do rebolo.

\section{RESULTADOS E DISCUSSÃO}

Neste tópico serão apresentados os resultados obtidos para a rugosidade, desgaste diametral do rebolo, emissão acústica, circularidade, microdureza e metalografia para ambas as técnicas de lubri-refrigeração utilizadas. Para análise das variáveis, foram convencionadas figuras com os respectivos desvios padrões da média dos três ensaios realizados.

\subsection{Rugosidade}

A Figura 3 apresenta a rugosidade média $\left(\mathrm{R}_{\mathrm{a}}\right)$ em função da velocidade de avanço para ambos os métodos estudados. 


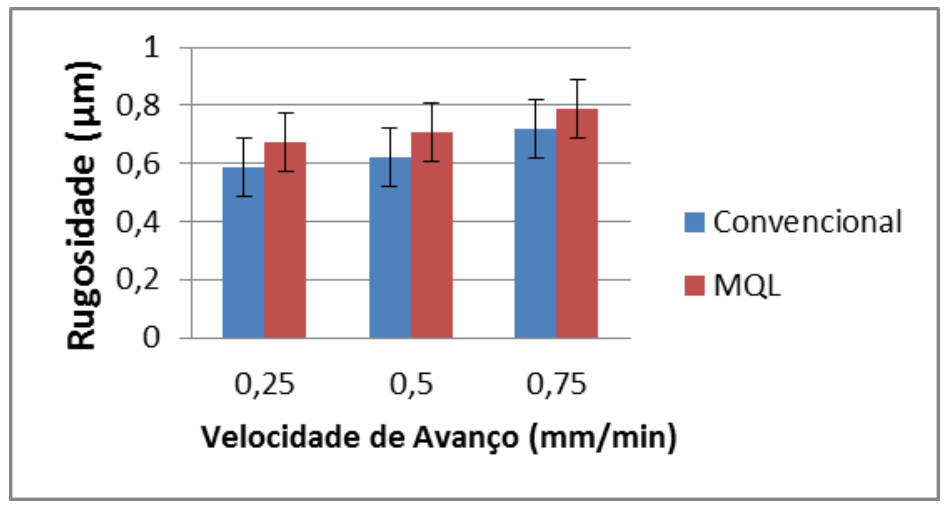

Figura 3: Rugosidade em função da velocidade de avanço para os sistemas convencional e MQL

Da figura 3, observa-se que os resultados foram adequados para o processo de retificação, estando todos os valores de rugosidade abaixo de 1,6 $\mu$ m [7]. Observa-se ainda a rugosidade média aumentou com a velocidade de avanço, como esperado, pois a tendência e de deterioração desta com a elevação da taxa de remoção de material. Mas sob uma análise sob a ótica estatística, não houve diferença entre os resultados em função do elevado desvio padrão apresentado nos mesmos. Em geral é muito difícil a reprodução de resultados de acabamento em retificação. Porém na média os resultados, eles assumiram uma tendência esperada. Esse fato ocorreu tanto para o método de lubri-refrigeração convencional como para técnica MQL. Apesar da pouca variação entre ambos os métodos, a usinagem com a aplicação convencional de fluido resultou em melhor acabamento, o que leva a crer que este tipo de aplicação atuou melhor na eliminação de cavaco e teve a função refrigeração se sobrepondo aquela de lubrificação, normalmente esperada pelo sistema MQL. Segundo Pereira et al. [15] e Marinescu et al. [11], a aplicação de fluido convencional, mesmo não sendo tão efetiva em relação à lubrificação em altas velocidades de corte, atua de maneira mais intensa quando trata-se de refrigeração, visto que, os rebolos de carbeto de silício verde são abrasivos de elevada dureza, gerando uma quantidade relativamente alta de calor na operação e elevando por sua vez a temperatura da interface de contato.

Quanto à refrigeração por MQL, esta se mostrou eficiente tendo em vista que os resultados de rugosidade são aceitáveis; mas vale destacar que não houve a formação de borra (problema normalmente relatado quando se emprega esta técnica em operações de retificação de metais). Segundo Barros et al. [3] devido à elevada energia de contato entre a ferramenta e a peça, ocorre um aumento significativo da temperatura na zona de corte. Aliado a isso, a borra (mistura de partículas metálicas com ar e óleo do MQL) fica mais propensa a se alojar nos poros do rebolo e então o cavaco (que não é completamente removido da zona de corte pelo fluido) acaba se alojando nos poros do rebolo. Como consequência negativa, ocorrer aumento da rugosidade da peça quando comparado ao método tradicional.

\subsection{Desgaste Diametral do Rebolo}

A Figura 4 apresenta o desgaste diametral do rebolo em função da velocidade de avanço para cada método de lubri-refrigeração utilizado.

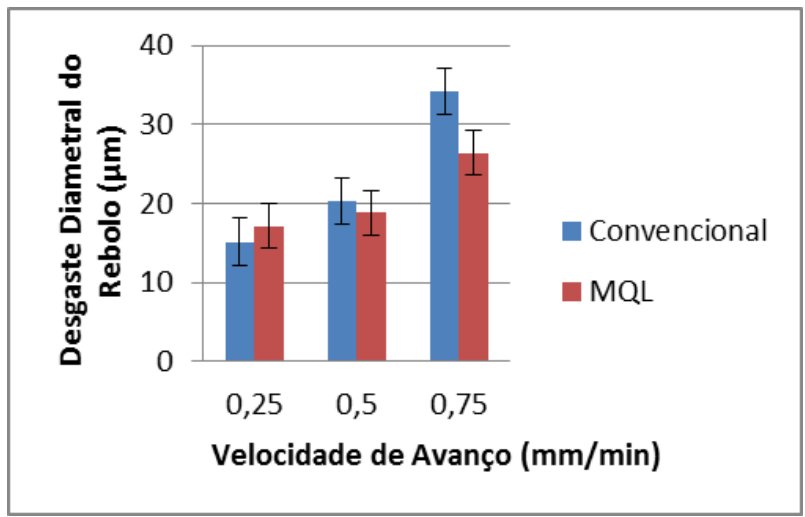

Figura 4: Resultados das medições de desgaste diametral do rebolo. 
Observa-se desta figura 4, que quando são utilizados ambos os processos de lubri-refrigeração, a tendência do comportamento do desgaste diametral do rebolo é o mesmo; ou seja, há o aumento desta variável com o aumento da velocidade de avanço, com o consequente aumento do atrito na região rebolo/peça, o que é um dos fatores de desgaste do rebolo [10]. Dos valores obtidos pode-se notar que não houve diferença estatística entre os mesmos.

Os valores de desgaste com a utilização do MQL em geral foram menores devido ao melhor efeito lubrificante desta técnica; ou seja, devido à elevada velocidade de aplicação do fluido de corte (se comparado com o método de refrigeração convencional), houve a quebra da barreira aerodinâmica com a melhor penetração do fluido na região de corte, melhorando a efetividade da lubri-refrigeração por este método e, portanto, proporcionando menores valores de desgaste diametral do rebolo.

Segundo Malkin [10] há três principais mecanismos de desgaste do rebolo que são: por atrito, pela fratura dos grãos abrasivos e do aglomerante. Destes, o desgaste devido ao atrito na maioria das vezes é o mais importante, pois tem como consequência a elevação das forças de corte e da taxa de fratura do aglomerante, contribuindo para que ocorra o desgaste volumétrico total do rebolo.

\subsection{Emissão Acústica}

A Figura 5 apresenta as medições de emissão acústica em função das diferentes velocidades de avanço para os métodos de lubri-refrigeração utilizados.

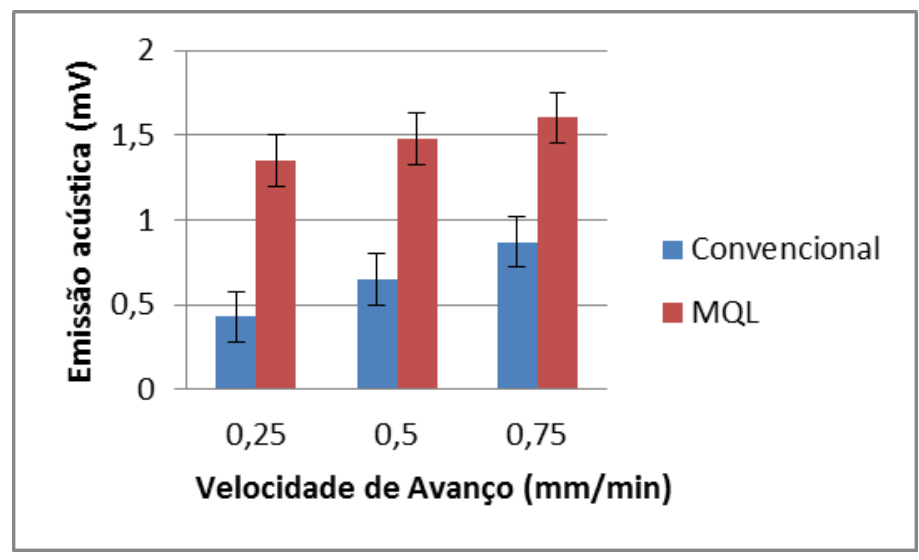

Figura 5: Resultados das medições de emissão acústica.

Oliveira et al. [14] afirmam que a emissão acústica está relacionada com a condição do processo de retificação e com as condições da superfície do rebolo e da peça. Todos os fenômenos físicos que ocorrem no processo (atrito, deformação plástica e elástica e remoção de cavaco) podem gerar emissão acústica. A emissão acústica é um tipo de energia que gera ondas elásticas que se propagam através do material e podem ser detectadas por sensores. A sua medição permite identificar queima do material.

Tanto nos ensaios onde foi utilizado o método convencional de lubri-refrigeração, como nos ensaios onde foi utilizado o MQL, há um aumento dos valores de emissão acústica conforme a velocidade de avanço aumentou. Isto ocorre, pois, a emissão acústica é uma função da velocidade de avanço. Os menores ruídos são gerados pela refrigeração convencional já que a densidade do fluido absorve o impacto e o atrito que ocorre entre o grão abrasivo e a peça gerando assim menor emissão acústica. Para uma condição severa de usinagem, ou seja, com alta velocidade de avanço, é de se esperar que aumente o atrito na região de corte e proporcionalmente o valor da emissão acústica. Nota-se que dos resultados apresentados não houve diferença estatística, mas uma tendência de crescimento com o aumento da velocidade de mergulho.

\subsection{Circularidade}

A Figura 6 apresenta as medições do desvio de circularidade dos corpos de prova usinados e compara-as segundo as velocidades de avanço e o método de lubri-refrigeração utilizado. Os ensaios com o sistema convencional resultaram nos maiores erros de circularidade, independente da velocidade de avanço empregada. Os desvios aumentaram com a velocidade de avanço para ambos os sistemas de lubri-refrigeração, o que já era esperado pois em condições mais severas há o aumento no atrito na região de contato entre o rebolo e a peça. O elevado atrito na região peça/rebolo, que por sua vez eleva a temperatura na zona de corte, é um dos 
principais fatores [13] que aumenta os desvios circularidade. Malkin [10] afirma que a geração de calor durante a usinagem promove dilatações e deformações térmicas, que acarretam maiores erros dimensionais e geométricos, como é o caso da circularidade.

É relevante destacar que na refrigeração convencional, o fluido de corte dificilmente penetra na região de contato entre o rebolo e a peça, o que gera maior atrito e consequente elevação da temperatura pela baixa lubri-refrigeração na região de corte. Em contrapartida a aplicação da MQL é feita mantendo-se a velocidade do jato de fluido igual à velocidade de corte, fazendo com que a lubri-refrigeração seja mais eficiente, ou seja menor atrito e consequentemente menor temperatura na região de contato.

Nos ensaios de retificação com a técnica MQL, nota-se que os erros de circularidade também aumentam, conforme o aumento na velocidade de avanço, porém sempre com valores abaixo da metade dos valores obtidos nos ensaios convencionais, o que mostra que o MQL atuou positivamente na redução do atrito na região de contato entre o rebolo e a peça, mesmo em altas velocidades de avanço, que acarretam condições mais agressivas de usinagem utilizadas neste trabalho. Assim, ao combinar a técnica MQL (altas velocidades do fluido) com o rebolo de SiC colaborou para a redução do atrito e na melhora da circularidade.

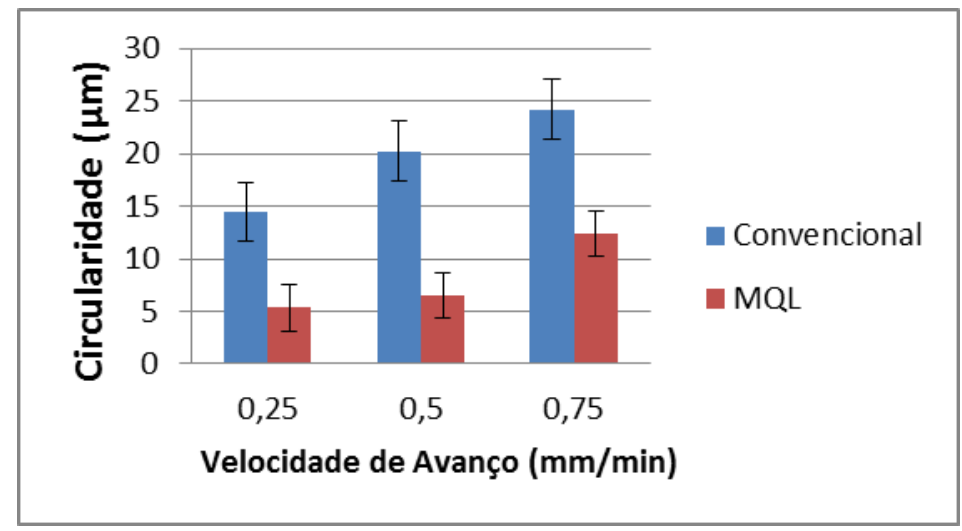

Figura 6: Resultados das medições de desvio de circularidade.

\subsection{Microdureza}

As medições de microdureza foram convertidas para a escala Rockwell C por ser amplamente utilizada, e apresentar maior facilidade de compreensão dos resultados. A figura 7 mostra os valores obtidos no ensaio de microdureza em todas as amostras estudadas.

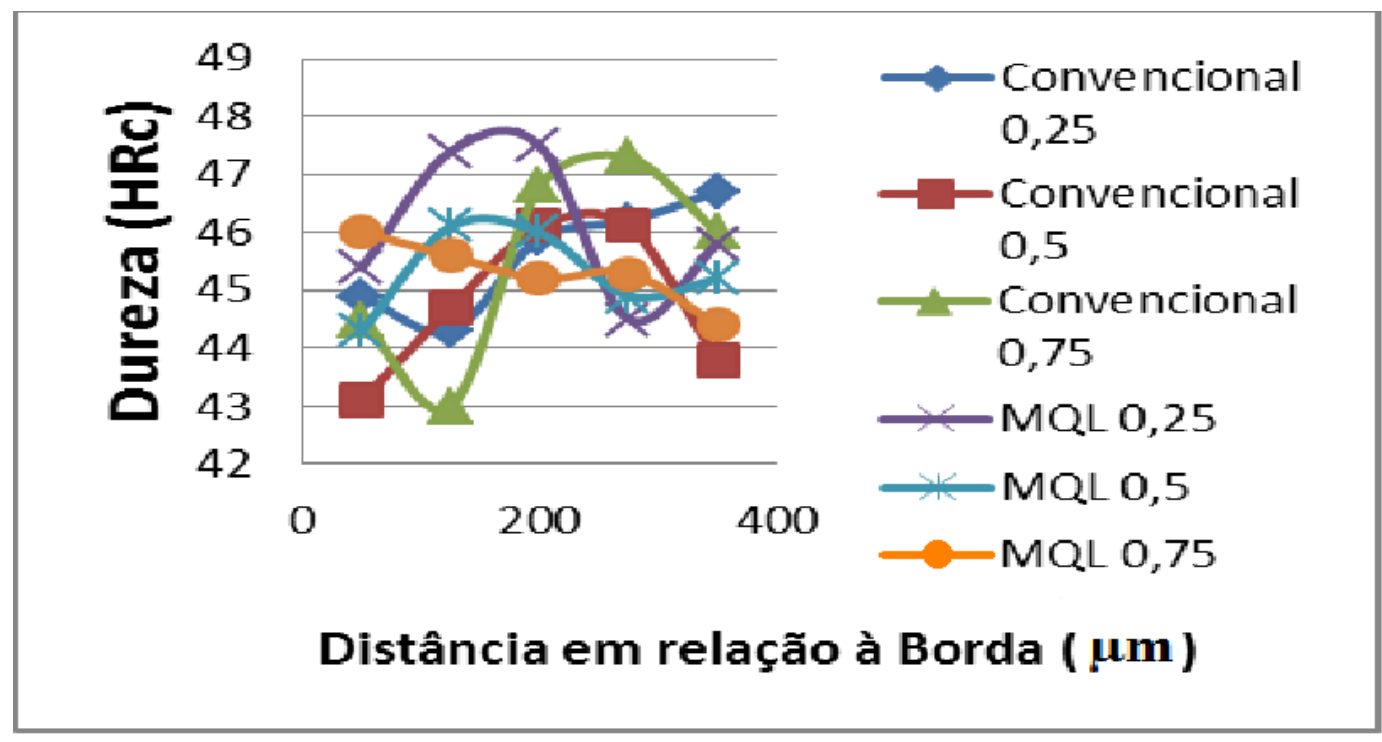

Figura 7: Resultados das medições de dureza para todos os ensaios.

Da figura 7 observa-se que não houve perda de dureza da peça abaixo da superfície de aço ABNT 
VP50 após a retificação com rebolo de SiC, independente do sistema de lubri-refrigeração empregado. Conforme informado pelo fabricante deste aço [16], a dureza média do material é de 43HRc. Neste caso, o valor

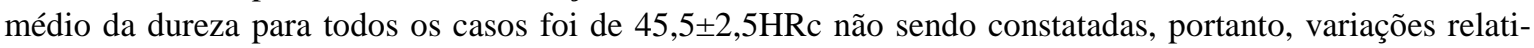
vamente expressivas nas leituras, podendo-se então, considerar que não ocorreram danos térmicos em nenhuma das técnicas apresentadas.

\subsection{Análise Metalográfica}

Nas figuras 8 e 9 estão as imagens das metalografias da peça obtidas para diferentes condições de librirefrigeração e velocidades de avanço iguais a $0,25 \mathrm{~mm} / \mathrm{min}$ e $0,75 \mathrm{~mm} / \mathrm{min}$, respectivamente. Como já mencionado previamente, o rebolo de carbeto de silício verde possui boas características térmicas e estabilidade química. Pelas imagens, observa-se que estas características também se manifestaram neste trabalho, pois de forma satisfatória evitou a ocorrência de transformações microestruturais tais como a queima ou trincas decorridas da usinagem nas condições investigadas neste trabalho. Estas observações também foram confirmadas pelos valores de microdureza (figura 7). Portanto, destas figuras, pode-se verificar que neste trabalho não houve influência negativa do sistema de lubri-refrigeração e nem da velocidade de avanço na integridade superficial do material.

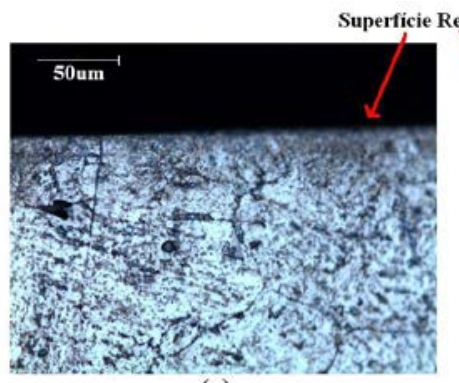

(a)

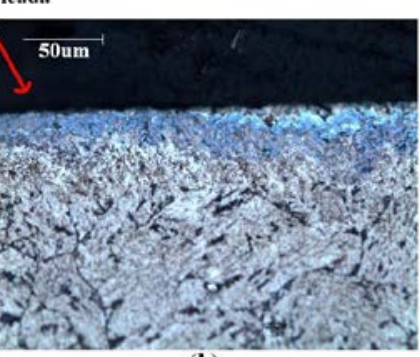

(b)

Figura 8: Imagens abaixo das superfícies retificadas com $\mathrm{V}_{\mathrm{f}}=0,25 \mathrm{~mm} / \mathrm{min}$ : (a) técnica convencional, (b) técnica MQL (ampliação de 500x)

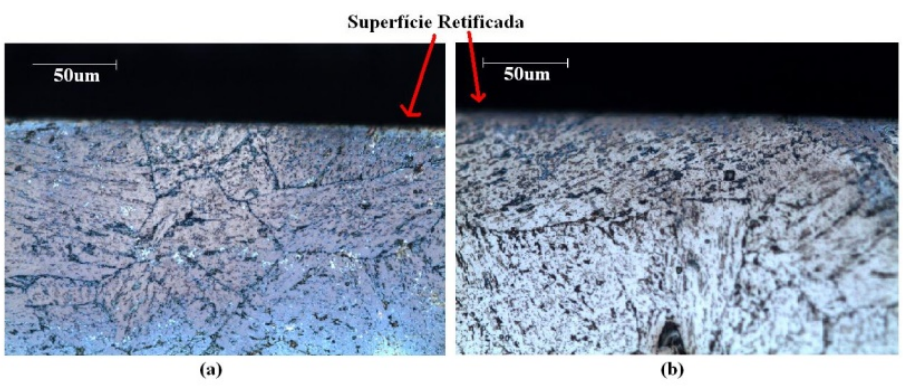

Figura 9: Imagens abaixo das superfícies retificadas com $V_{f}=0,75 \mathrm{~mm} / \mathrm{min}$ : (a) técnica convencional, (b) técnica $\mathrm{MQL}$ (ampliação 500x)

Em relação às manchas azuis mais claro, mais presentes na parte (b) da Figura 8 são características da presença de álcool, resultante de provável falha na secagem dos corpos de prova antes da metalografia.

\section{CONCLUSÕES}

Analisando os dados obtidos nos ensaios de retificação do aço VP50 com rebolo de carbeto de silício verde, com diferentes condições de corte as seguintes conclusões podem ser tiradas:

1. A rugosidade da peça aumentou com a velocidade de avanço, independente da velocidade de corte empregada e do sistema de lubri-refrigeração testado. Estatisticamente não se observou diferença entre os valores gerados após a retificação com os dois sistemas;

2. Todos os valores de rugosidade $(\mathrm{Ra})$ situaram-se abaixo de $1,6 \mu \mathrm{m}$;

3. O comportamento para o desgaste do rebolo, desvios de circularidade e para o sinal de emissão acústica foram os mesmos da rugosidade, ou seja, eles aumentaram com a velocidade de avanço. Mas em relação ao sistema de lubri-refrigeração, o comportamento foi diferente. Os menores va- 
lores de desgaste diametral e dos desvios de circularidade foram observados após a usinagem com a técnica MQL, enquanto que para o sinal de emissão acústica, o sistema convencional de aplicação de fluido de corte foi aquele de melhor desempenho;

4. Ao analisar a microdureza e por meio das imagens abaixo da superfície retificadas, conclui-se que não houve alteração microestrutural nas condições investigadas;

5. A implementação do sistema MQL, comparada com o sistema convencional de aplicação de fluido de corte, na retificação do aço ABNT VP 50 nas condições investigadas proporcionou redução substancial no volume de fluído utilizado.

\section{AGRADECIMENTOS}

Agradecimentos especiais a FAPESP (Fundação de Amparo à Pesquisa do Estado de São Paulo), processos 2012/13688-8 e 2012/13852-2, pelos recursos financeiros disponibilizados para esta pesquisa a empresa ITW pela doação dos fluidos utilizados no sistema MQL e a empresa SIVAT pela doação do rebolo utilizado.

\section{BIBLIOGRAFIA}

[1] ALBERDI, R., SANCHEZ, J. A., POMBO, I., et al., "Strategies for Optimal use of Fluids in Grinding”, International Journal of Machine Tools and Manufacture, v. 51, n. 6, pp. 491-499, March 2011.

[2] BABIC, D., MURRAY, D. B., TORRANCE, A. A., "Mist jet cooling for grinding processes”, International Journal of Machine Tools and Manufacture, v. 45, n. 10, pp. 1171-1177, August 2005.

[3] BARROS, B. G., SILVA, T., CANARIM, R. C., et al., "Utilization of teflon an aluminum oxide for wheel cleaning in minimun quantity lubrification (MQL) grinding”, Materials Research, v. 17, n. 01, pp. 8896, February 2013.

[4] BARTZ, W.J., “Lubricants and The Environment”, Tribology International, v. 31, n. 1-3, pp. 35-47, January 1998.

[5] BRIAN R. W., Principles of Modern Grinding Technology, 1 ed., Burlington, William Andrew Publishing, 2009.

[6] CHEN, X., ROWE, W.B. "Analysis and simulation of the grinding process, Part I: Generation of the grinding wheel surfacel”, International Journal of Machine Tools and Manufacture. v. 36, n. 8, pp. 871-882, August 1990.

[7] DINIZ, A.E., MARCONDES, F.C., COPPINI, N.L., Tecnologia da usinagem dos materiais., 4 ed., São Paulo, Artiliber Editora Ltda, 2003.

[8] EBBRELL, S., WOOLLEY, N. H., TRIDIMAS, Y. D., et al., “The Effects of Cutting Fluid Application Methods on the Grinding Process”, International Journal of Machine Tools and Manufacture, v.40, n. 2, pp. 209-223, January 2000.

[9] IRANI, R. A., BAUER, R. J., WARKENTIN, A., “A review of cutting fluid application in the grinding process”, International Journal of Machine Tools and Manufacture, v. 45, n. 15, pp. 1696-1705, December 2005.

[10] MALKIN, S., Grinding Technology: Theory and Applications of Machining with Abrasives. 2 ed., South Norwalk Industrial Press Inc., 2008.

[11] MARINESCU, I. D., HITCHNER M., UHLMANN E. Handbook of Machining with Grinding Wheels\|,1 ed., Boca Raton, CRC Press, 2007.

[12] MARINESCU, I. D., ROWE, W.B., DIMITROV, B., et al, Tribology of abrasive machining processes. 1 ed., Norwich, William Andrew Inc, 2004.

[13] MINKE, E., “Contribution to the role of coolants on grinding process and work results”. In: 3rd International Machining \& Grinding Conference, v. 1, pp. 13-32, Cincinnati, October 1999.

[14] OLIVEIRA, D. J., GUERMANDO, L. G., BIANCHI, E. C., et al, "Improving minimum quantity of lubrification in CBN grinding using compressed air wheel cleaning”, Journal os Machine Processing Technology, v. 212, n. 12, pp. 2559-2568, December 2012.

[15] PEREIRA, C., CORREA, S.J., PIVATO, C. “Como se apresentam e para que servem os lubrificantes e refrigerantes”. In: Revista Máquinas \& Metais, Aranda editora técnica e cultural pp. 352-361, abril, 2005.

[16] Villares Metals - Catálogo de Aços para Moldes. 2010

[17] WALKER, T., MQL Handbook, 1 ed., Unist Inc., 2013. 